\title{
Studying the Water Transport in a Proton Exchange Membrane Fuel Cell by Neutron Radiography and Relative Humidity Sensors
}

\author{
Yong-Song Chen ${ }^{1}$ \\ Huei Peng \\ Department of Mechanical Engineering, \\ University of Michigan, \\ 1231 Beal Avenue, \\ Ann Arbor, Ml 48109-2121
}

Water management in a fuel cell is essential to ensure cell performance and life. In this study, a special single cell was designed for the purpose of detecting liquid water and water vapor simultaneously. The major difference between our design and traditional flow field designs is the fact that the anode and cathode channels were shifted sideways, so that they do not overlap in the majority of the active areas. The liquid water is measured by using neutron radiography located at the National Institute of Standards and Technology. The water vapor is measured by the 20 relative humidity sensors embedded in the anode and cathode flow field plates. The effects of the relative humidity and stoichiometry of the cathode inlet on relative humidity distribution in the channels and on water accumulation in the gas diffusion layers (GDLs) were investigated in this study. The liquid water accumulation at steady-state was calculated by using imaging mask techniques and least-squares method. The transient behavior of water transport was detected and recorded when a step load change was applied on the cell. It is demonstrated that liquid water tends to accumulate in the gas diffusion layers under the rib. Moreover, the transient behavior of liquid water transport in the GDL and the relative humidity distribution in both the anode and cathode channels at different operating conditions are discussed. [DOI: 10.1115/1.3006312]

Keywords: fuel cell, water management, relative humidity, neutron radiography

\section{Introduction}

Proton exchange membrane fuel cells (PEMFCs) are widely studied for mobile power applications because of their high efficiency, low operating temperature, and benign exhaust byproducts. A key challenge in PEMFC research was found to be the low membrane conductivity under adverse conditions, including high temperature and low water content. As membrane humidity increases, its protonic conductivity increases. However, too much water could cause flooding in flow channels or gas diffusion layers (GDLs), decreasing the performance of a fuel cell. Many fuel cell models have been published to investigate the effect of water content on cell performance.

Bernardi and Verbrugge [1,2] developed one of the early mathematical models. Their model was a steady-state one-dimensional model, which described reactant transports in GDLs and water balance in PEMFCs. The membrane in their model was assumed fully hydrated, which is not the real operation of PEMFCs. Springer et al. [3] developed a model with partially hydrated membrane. They empirically related the membrane conductivity to the water content of membrane. Wang et al. [4] and Um et al. [5] developed two-dimensional models based on computational fluid dynamics (CFD). All the models referred to above did not consider the influence of liquid water on cell performance. Fuller and Newman [6] developed a model that described the water and thermal management of a fuel cell. Baschuk and $\mathrm{Li}$ [7] developed a model that includes the effect of "degree of water flooding" in the cathode catalyst layer and in the cathode GDL on the cell performance. Wang et al. [8] and Pasaogullari and Wang [9] con-

\footnotetext{
${ }^{1}$ Corresponding author.
}

Manuscript received June 17, 2007; final manuscript received January 28, 2008; published online June 8, 2009. Review conducted by Nigel M. Sammes. Paper presented at the 5th International Fuel Cell Science Engineering and Technology Conference (FUELCELL2007), Brooklyn, NY, June 18-20, 2007. sidered the liquid water transport in hydrophobic GDL and the effect of flooding on the cell performance. Natarajan and Nguyen [10] and Lin and Nguyen [11] developed two-phase flow models for the cathode of PEMFCs to describe the liquid saturation distribution in the GDLs under the channels and under the ribs. The liquid saturation in the above studies was derived based on empirical equations, and the results were not validated by experiments. Thus, experimental results that can measure liquid water distribution in a PEMFC, and more importantly, results that provide cathode/anode and under the channel/under the rib differentiation can be very helpful in the advancement of fuel cell models.

Conducting experiments to measure water distribution inside an operating PEMFC is nontrivial because these experiments need special facilities. The water vapor in the flow channels can be measured by relative humidity (RH) sensors. Nishikawa et al. [12] used a RH sensor to measure RH along the cathode flow channels. However, RH sensors can measure water vapor but not liquid water. In addition, a major issue with relative humidity sensors is the fact that when they are exposed to a near-saturated gas, the reading saturates, and even when they are subsequently exposed to under-saturated gases, the sensor reading may stay saturated for up to several minutes. Since it is desirable to operate PEMFC near-saturated condition, RH sensor alone is not a good solution. Mench et al. [13] measured the in situ water vapor distribution in a working PEMFC by using gas chromatography. These methods can detect water vapor in the flow channels only. However, in a working fuel cell, liquid water is generated in the cathode catalyst layer of the cell due to a chemical reaction. And it is mainly the liquid water in the GDL that affects cell performance through the catalyst and flow blockage. Therefore, it is more important to measure liquid water accurately than to measure water vapor.

Tüber et al. [14] designed a fuel cell with its cathode covered by transparent plexiglass to observe the liquid water in the flow channels. They used a digital camera to record the images of 
liquid water generated in the cathode side of flow channels. However, this optical method cannot observe the liquid water in the GDL, and quantifying liquid water accurately is also a challenge.

Neutron radiography technique has been used for an in situ and nondestructive visualization and measurement technique for liquid water in a working fuel cell [15-23] because neutron transmissibility is sensitive to hydrogen, which is an element of a water molecule. Pekula et al. [15] used neutron radiography to observe the distribution of liquid water and measure the liquid drop velocity at various operating conditions. Chuang et al. [16] quantified liquid water in the GDLs and flow channels of PEMFCs under both flooded and nonflooded conditions. Their results show that cell performance was affected by a few tenths of a milligram of liquid water in the fuel cell. Turhan et al. [17] conducted neutron imaging experiments to study the influence of operating parameters on the liquid water distribution and accumulation. Their results indicated that liquid water accumulation in the fuel cell decreases with increasing gas flow rate of inlet.

Geiger et al. [18] used neutron radiography to observe liquid water distribution in a PEMFC after it was shut down and cooled to ambient temperature. The liquid water was observed to accumulate in the bottom part of flow field. Kramer et al. [19] applied statistical methods to neutron radiography experiments to quantify liquid water within a working PEMFC to compare serpentine and interdigitated flow field designs. Zhang et al. [20] studied the impact of GDL materials on liquid water accumulation inside a PEMFC.

Many researchers used the neutron imaging facility in the National Institute of Standards and Technology (NIST) to investigate the water content in an operating fuel cell. Trabold et al. [21] discussed the water accumulation in a serpentine flow field and the effects of current density and cathode stoichiometry on water accumulation. Owejan et al. [22] used a fuel cell with an interdigitated cathode flow field to study the effect of cathode inlet RH on water accumulation. Hickner et al. [23] focused on the transient behavior of liquid water transport inside a PEMFC and the effect of local heating on the accumulation and distribution of liquid water.

References [15-23] captured neutron images when fuel cells were at steady-state conditions, and they used fuel cells that have overlapped and identical anode and cathode flow fields, making it difficult to differentiate liquid water between the anode and cathode in neutron imaging. It is known that the reaction in the cathode side is considered the rate determining step because of the slow kinetics of oxygen reduction. Liquid water in the channel does not influence cell performance unless the channel is filled with liquid water. It is the liquid water accumulation in the cathode catalyst layer or in the cathode GDL that could cause the mass-transfer limitation of oxygen. Pasaogullari and Wang [9] and Djilali [24] proposed different mechanisms of liquid water transport in the GDL. However, their hypotheses described the GDL under the channel without considering the GDL under the rib. The studies of Turhan et al. [17] and Zhang et al. [20] showed that more liquid water accumulates in the GDL under the rib than in the GDL under the channel. Thus, the influence of liquid water in the GDL under the rib cannot be neglected.

Recently we developed a PEMFC model capable of predicting liquid saturation precisely. In our hypothesis, due to the gas flow in the channel, liquid water has a tendency to accumulate in the GDL under the rib. When the GDL under the ribs cannot hold more liquid water, the liquid water emerges from the corner of the ribs and GDL to the channels. The mechanism is depicted in Fig. 1. In order to understand the influence of operating conditions on cathode liquid saturation in the GDL, we need to conduct experiments that can help differentiate liquid water in the cathode GDL.

In the present study, a specially designed fuel cell was used, and the water distribution at both saturated and undersaturated conditions were investigated. The liquid water distribution and accumulation inside the fuel cell were studied by using neutron radiogra-

(a)

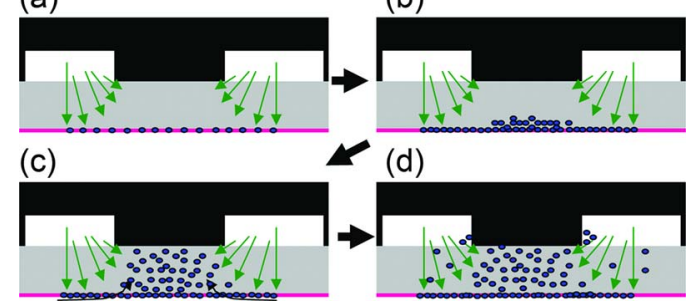

Fig. 1 Schematic of the mechanism for liquid water transport in the GDL

phy and image masking technique. The water vapor was detected by $20 \mathrm{RH}$ sensors embedded in the single cell. The effect of cathode inlet RH and stoichiometry were discussed. The transient behaviors of liquid water and water vapor were also studied in this study. The sensor data will be used to validate our model in the future.

\section{Experimental Method}

2.1 Fuel Cell Design. In order to differentiate liquid water between different locations, a specially designed single cell embedded with 20 miniature RH sensors was manufactured for this study. The membrane electrode assembly (MEA) with an active area of $100 \mathrm{~cm}^{2}$ was made by Umicore (http:// www.umicore.com/). The MEA consists of a $25 \mu \mathrm{m}$ thick membrane, $0.4 \mathrm{mg} \mathrm{Pt} \mathrm{cm}{ }^{-2}$ in both anode and cathode catalyst layers, and $230 \mu \mathrm{m}$ thick GDLs that were made of carbon papers.

Most published neutron radiography experiments used identical anode and cathode flow fields for which it was not easy to differentiate liquid water between the anode and cathode. In this study, the flow fields of the anode and cathode were shifted to minimize overlap. Both anode and cathode flow field plates are made of graphite. Before being machined with flow channels, these graphite plates were densified with resign to reduce the porosity, which could trap liquid water and affect the accuracy of experimental data. The anode flow field is a six-channel serpentine pattern with a channel width and a channel depth of $1.6 \mathrm{~mm}$ and $1.0 \mathrm{~mm}$, respectively. The rib width is $1.7 \mathrm{~mm}$. The cathode flow field has 12 straight parallel channels from the inlet and 6 channels to the outlet. The idea is to increase the gas flow rate by reducing the cross-section area of the overall flow area. The dimensions of flow channels and ribs are the same with those in the anode. The flow fields of the anode and cathode are shown in Fig. 2. The rectangular holes in those flow fields indicate RH sensor locations.

The RH sensors used in this study are type SHT75 made by Sensirion, one of the smallest RH sensors we could find on the market. Its cross-section dimension is $3.7 \times 2.2 \mathrm{~mm}^{2}$. Each sensor penetrated through the flow field plate such that the sensor head was inside the fuel cell and leads were outside the fuel cell, as shown in Fig. 3.

(a)

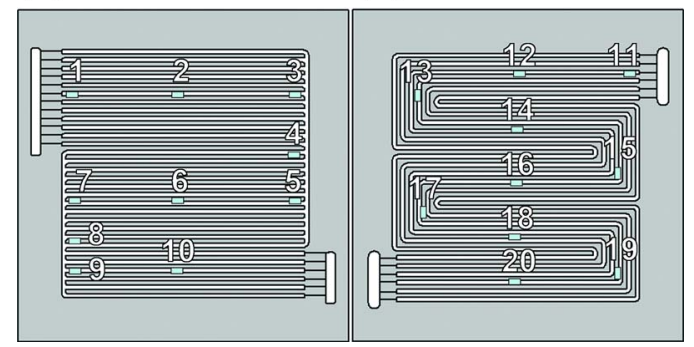

Fig. 2 Flow field design used in this study: (a) cathode and (b) anode. The rectangular holes are the positions of relative humidity sensors. 


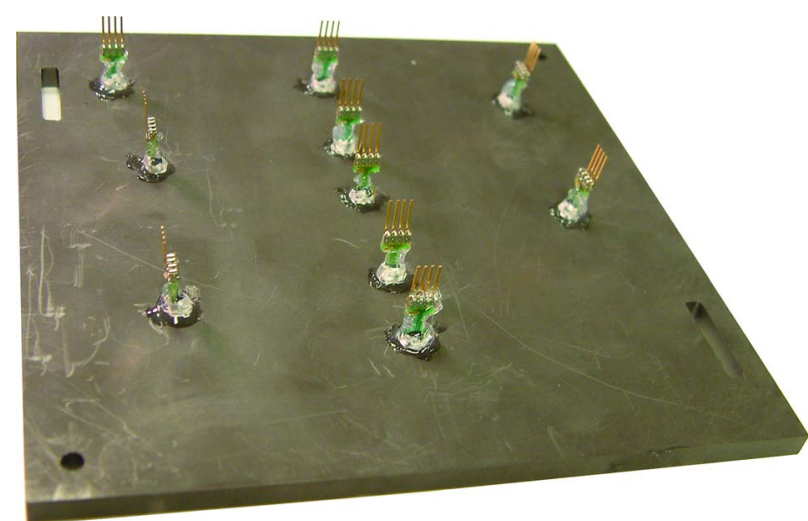

Fig. 3 A flow field plate embedded with ten relative humidity sensors

The current collectors are made of gold-plated copper plates, and the end plates are made of aluminum alloy. All current collectors and end plates have circular holes corresponding to the $\mathrm{RH}$ sensor positions. The cell assembly is compressed by using 12 bolts with nuts.

2.2 Experimental Setup and Procedures. The experiments were conducted at the NIST Center for Neutron Research (NCNR). The experimental setup in this study was for the purpose of measuring liquid water and water vapor simultaneously. The experimental setup is depicted in Fig. 4(a). Figure 4(b) shows the single cell embedded with RH sensors. Thin wires were soldered on the sensor leads to connect signal cables with the signal processing unit (EK-H3). The RH and temperature were measured and recorded for each of the 20 sensors.

The neutron radiography experiments were conducted by using a thermal neutron beam at Beam Tube 2 (BT-2) at the NCNR. This facility was discussed in Ref. [25]. Neutron images were captured by a $\mathrm{Li}^{6}$-doped $\mathrm{ZnS}$ scintillator placed directly in contact with an amorphous silicon flat panel detector that has a pixel pitch of $0.127 \mathrm{~mm}$ and spatial resolutions of about $0.250 \mathrm{~mm}$ at a frame rate of $1 \mathrm{~Hz}$ and about $0.125 \mathrm{~mm}$ at a frame rate of $15 \mathrm{~Hz}$. The following will illustrate the experimental procedure for steadystate and transient images.

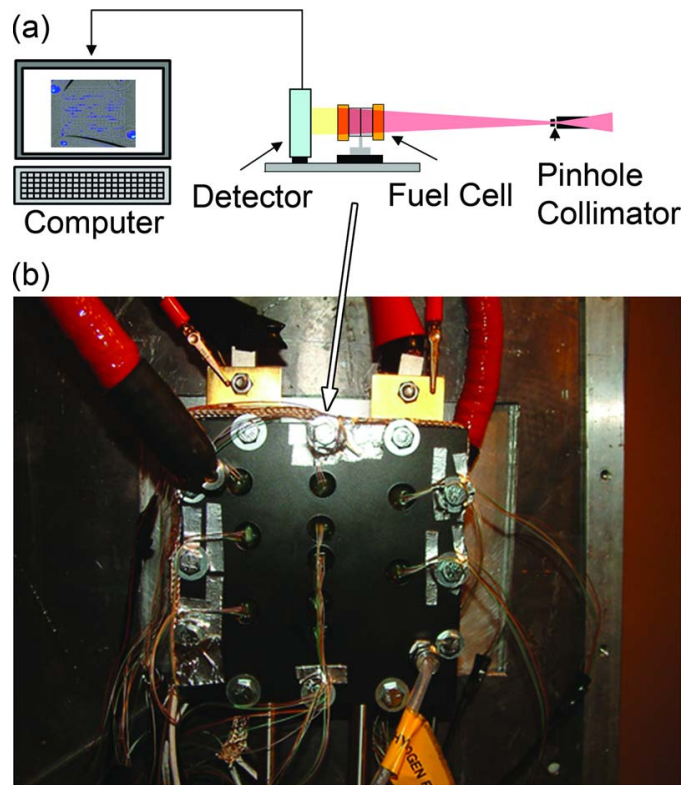

Fig. 4 (a) Schematic of the experimental setup. (b) The single cell.

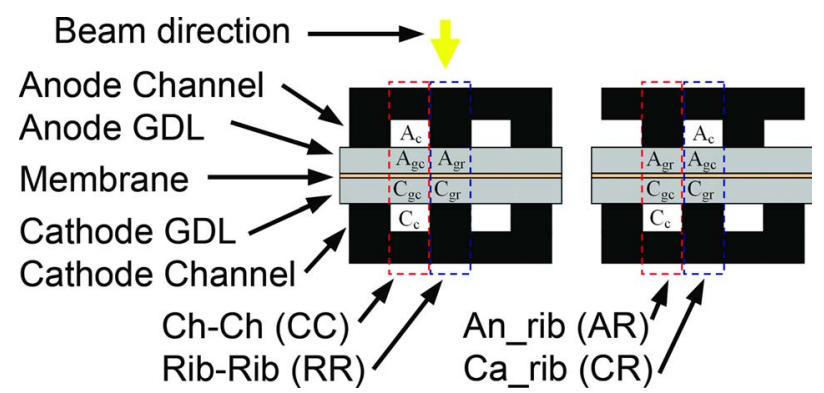

Fig. 5 Schematic of water accumulation in six areas

The steady-state images are used to study the effect of stoichiometry values and $\mathrm{RH}$ values of the cathode inlet on the water content. The cell temperature was controlled at $70^{\circ} \mathrm{C}$. A reference image was obtained by averaging a series of 1000 images that were taken when the cell was purged with dry nitrogen and dry air on the anode and cathode sides, respectively. The water content in the cell is calculated by comparing the difference between the reference image and test images. The test images were taken when the cell was working at selected conditions. The operating current densities were selected at $0 \mathrm{~A} \mathrm{~cm}^{-2}, 0.1 \mathrm{~A} \mathrm{~cm}^{-2}, 0.4 \mathrm{~A} \mathrm{~cm}^{-2}$, $0.5 \mathrm{~A} \mathrm{~cm}^{-2}$, and $0.6 \mathrm{~A} \mathrm{~cm}^{-2}$ (or $0.7 \mathrm{~A} \mathrm{~cm}^{-2}$ ). For each current density, the cell was operated at two relative humidity values, $50 \%$ and $100 \%$, and three stoichiometric values, 2, 3, and 4, of inflow air. The hydrogen was not humidified, and the anode stoichiometry was 1.2 for all experiments with a minimum flow rate set at levels corresponding to $0.2 \mathrm{~A} \mathrm{~cm}^{-2}$.

The purpose of transient images is to study the variation of water content in the fuel cell during step load changes. The experimental setup for transient images was the same as that for steady-state images except that the frame rate was set at $15 \mathrm{fps}$. The anode gas was not humidified, and the RH of the cathode inlet gas was selected at $50 \%$ and $100 \%$. The stoichiometric values of the anode and cathode were 1.2 and 3, respectively, for all experiments except that a minimum flow rate for both the cathode and anode was set at levels corresponding to $0.2 \mathrm{~A} \mathrm{~cm}^{-2}$. Four different changes in current density were selected in this experiment: from $0 \mathrm{~A} \mathrm{~cm}^{-2}$ to $0.1 \mathrm{~A} \mathrm{~cm}^{-2}$, from $0.1 \mathrm{~A} \mathrm{~cm}^{-2}$ to $0.4 \mathrm{~A} \mathrm{~cm}^{-2}$, from $0.4 \mathrm{~A} \mathrm{~cm}^{-2}$ to $0.6 \mathrm{~A} \mathrm{~cm}^{-2}\left(0.7 \mathrm{~A} \mathrm{~cm}^{-2}\right)$, and from $0.6 \mathrm{~A} \mathrm{~cm}^{-2}\left(0.7 \mathrm{~A} \mathrm{~cm}^{-2}\right)$ to $0 \mathrm{~A} \mathrm{~cm}^{-2}$.

2.3 Image Processing. Steady-state images and transient images were analyzed by different procedures due to the trade-off in time and spatial accuracy. Ten captured images were averaged to obtain a final steady-state image. The liquid water amount was calculated by using neutron beam calibration codes developed at the NIST. In this study, due to the shift in anode and cathode channels, there are four types of data, depending on the geometric locations, as shown in Fig. 5. These combinations are called "ChCh," "Rib-Rib," "Ca_rib," and "An_rib" in this study. These four areas can be distinguished by image masking techniques. Four masks were created to block unwanted areas, as shown in Fig. 6. In processing transient images, ten images were averaged to obtain moving average images. The same four masks shown in Fig. 6 were also applied to differentiate the water content in four areas. In addition, the active area of this single cell is too large to be regarded as a single uniform cell, so in the image analysis the active area was divided into 15 segments along the anode flow channels, as shown in Fig. 7. The average liquid water thickness was then calculated in each of the 15 segments.

\section{Results and Discussion}

The calculated liquid water thickness can be visualized by colorizing the neutron density images, as shown in Fig. 8. As can be seen, much water accumulates in the bottom half of the cell. How- 
(a)

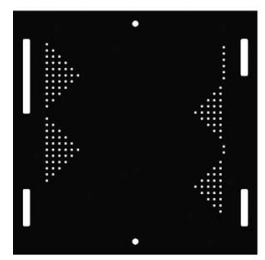

(c)

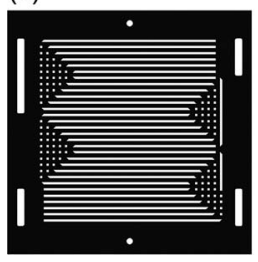

(b)

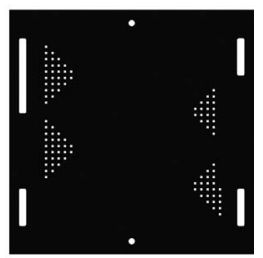

(d)

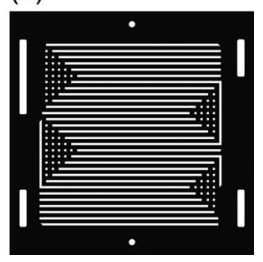

Fig. 6 Four masks used to quantify liquid water in (a) $\mathrm{Ch}-\mathrm{Ch}$, (b) Rib-Rib, (c) Ca_rib, and (d) An_rib areas

ever, these images only provide information about the water distribution in the $X-Y$ direction but not in the $Z$ (into the paper) direction. The measured liquid water could be in the anode/ cathode GDLs or anode/cathode channels. As explained before, differentiating the liquid water location more precisely is necessary because water in the flow channel does not influence cell performance nearly as much as water in the GDL. Therefore, a method is introduced in the next section to differentiate liquid water along the $Z$ direction.

3.1 Differentiating Liquid Water at Six Locations. Liquid water within a PEMFC could accumulate in six types of locations, as shown in Fig. 5: anode channel $\left(A_{c}\right)$, anode GDL under the channel $\left(A_{g c}\right)$, anode GDL under the rib $\left(A_{g r}\right)$, cathode channel $\left(C_{c}\right)$, cathode GDL under the channel $\left(C_{g c}\right)$, and cathode GDL under the rib $\left(C_{g r}\right)$. We can express the relationship between water thicknesses in those six locations and measured data rib-rib (RR), channel-channel (CC), cathode_rib (CR), and anode_rib (AR) as

$$
\begin{gathered}
A_{g r}+C_{g r}=\mathrm{RR} \\
A_{c}+A_{g c}+C_{g c}+C_{c}=\mathrm{CC} \\
A_{c}+A_{g c}+C_{g r}=\mathrm{CR} \\
A_{g r}+C_{c}+C_{g c}=\mathrm{AR}
\end{gathered}
$$

or in a matrix form

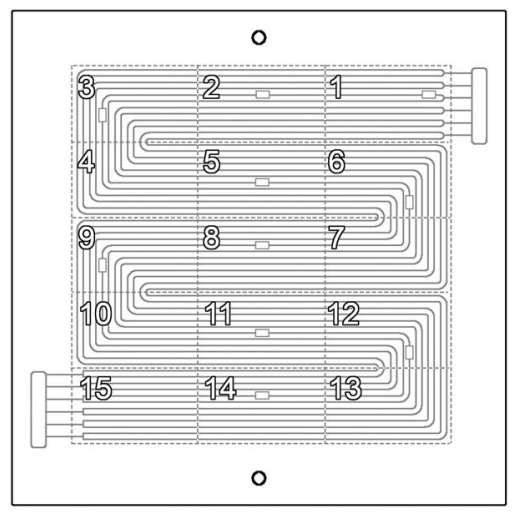

Fig. 7 The active area is divided into 15 segments. Segments are numbered successively along the anode flow channels.

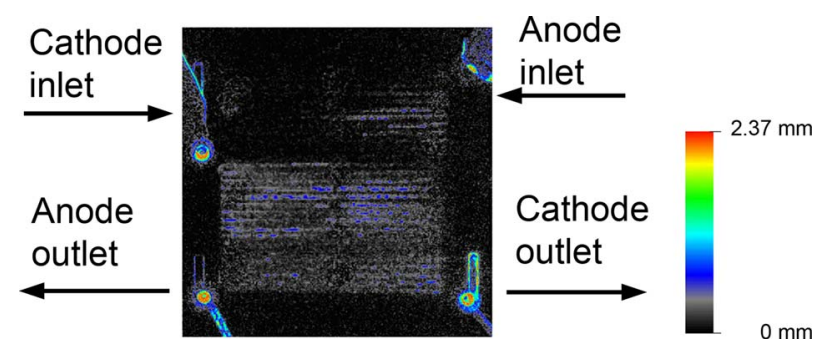

Fig. 8 A colorized neutron image (current density: $0.4 \mathrm{~A} \mathrm{~cm}^{-2}$; anode/cathode stoichiometry: 1.2/3; cathode inlet RH: 100\%)

$$
\mathbf{A x}=\mathbf{b}
$$

where

$$
\mathbf{A}=\left[\begin{array}{llllll}
0 & 0 & 1 & 0 & 0 & 1 \\
1 & 1 & 0 & 1 & 1 & 0 \\
0 & 0 & 1 & 1 & 1 & 0 \\
1 & 1 & 0 & 0 & 0 & 1
\end{array}\right], \quad \mathbf{x}=\left[\begin{array}{c}
C_{c} \\
C_{g c} \\
C_{g r} \\
A_{c} \\
A_{g c} \\
A_{g r}
\end{array}\right], \quad \mathbf{b}=\left[\begin{array}{c}
\mathrm{RR} \\
\mathrm{CC} \\
\mathrm{CR} \\
\mathrm{AR}
\end{array}\right]
$$

There are six unknowns and four equations for each of the 15 segments. Overall, there are 90 unknowns and 60 equations. We can solve the water content in 15 segments at the same time. The relationship between water content in 90 locations and 60 measured data is expressed in an augmented matrix form,

$$
\left[\begin{array}{cccccc}
\mathbf{A} & \mathbf{O} & \mathbf{O} & \mathbf{O} & \cdots & \mathbf{O} \\
\mathbf{O} & \mathbf{A} & \mathbf{O} & \mathbf{O} & \cdots & \mathbf{O} \\
\mathbf{O} & \mathbf{O} & \mathbf{A} & \mathbf{O} & \cdots & \mathbf{O} \\
\mathbf{O} & \mathbf{O} & \mathbf{O} & \mathbf{A} & \cdots & \mathbf{O} \\
\vdots & \vdots & \vdots & \vdots & \ddots & \vdots \\
\mathbf{O} & \mathbf{O} & \mathbf{O} & \mathbf{O} & \cdots & \mathbf{A}
\end{array}\right]\left[\begin{array}{c}
\mathbf{x}_{1} \\
\mathbf{x}_{2} \\
\mathbf{x}_{3} \\
\mathbf{x}_{4} \\
\vdots \\
\mathbf{x}_{15}
\end{array}\right]=\left[\begin{array}{c}
\mathbf{b}_{1} \\
\mathbf{b}_{2} \\
\mathbf{b}_{3} \\
\mathbf{b}_{4} \\
\vdots \\
\mathbf{b}_{15}
\end{array}\right]
$$

where $\mathbf{A}, \mathbf{x}_{i}$, and $\mathbf{b}_{i}$ are defined in Eq. (3) for the $i$ th segment. $\mathbf{O}$ is a zero matrix with the same size as $\mathbf{A}$.

Equation (4) is an underdeterminant problem, and a unique solution does not exist. In addition, matrix $\mathbf{A}$ is not a full rank because $A_{g c}$ and $A_{c}$ always co-exist, and $C_{g c}$ and $C_{c}$ always coexist. Since $A_{g c}$ and $A_{c}$ are not differentiable, they are considered as a single unknown, and so are $C_{g c}$ and $C_{c}$. Then there are four unknowns and four measurements in each segment; $A_{g r}$ and $C_{g r}$ can be solved exactly.

After the above procedure, 30 unknowns are solved, and 60 unknowns remain; however, there are only 45 equations left. The problem is still "too underdeterminant" to yield accurate data. To reduce the number of unknowns, we need to make an assumption. According to Turhan et al. [17], liquid water inside a fuel cell significantly decreases with increasing gas flow rate. This is because the GDL is made of hydrophobic and porous materials, and a large gas flow rate helps push liquid water out from the GDL, resulting in less liquid water accumulation in the GDL. To simplify the problem, the water thicknesses in the GDL under the channel are assumed to be inversely proportional to the gas flow rate,

$$
\begin{gathered}
C_{g c}=\frac{\alpha}{N_{c a}} \\
A_{g c}=\frac{\beta}{N_{a n}}
\end{gathered}
$$

Under these assumptions, the remaining unknowns and equations are expressed as 

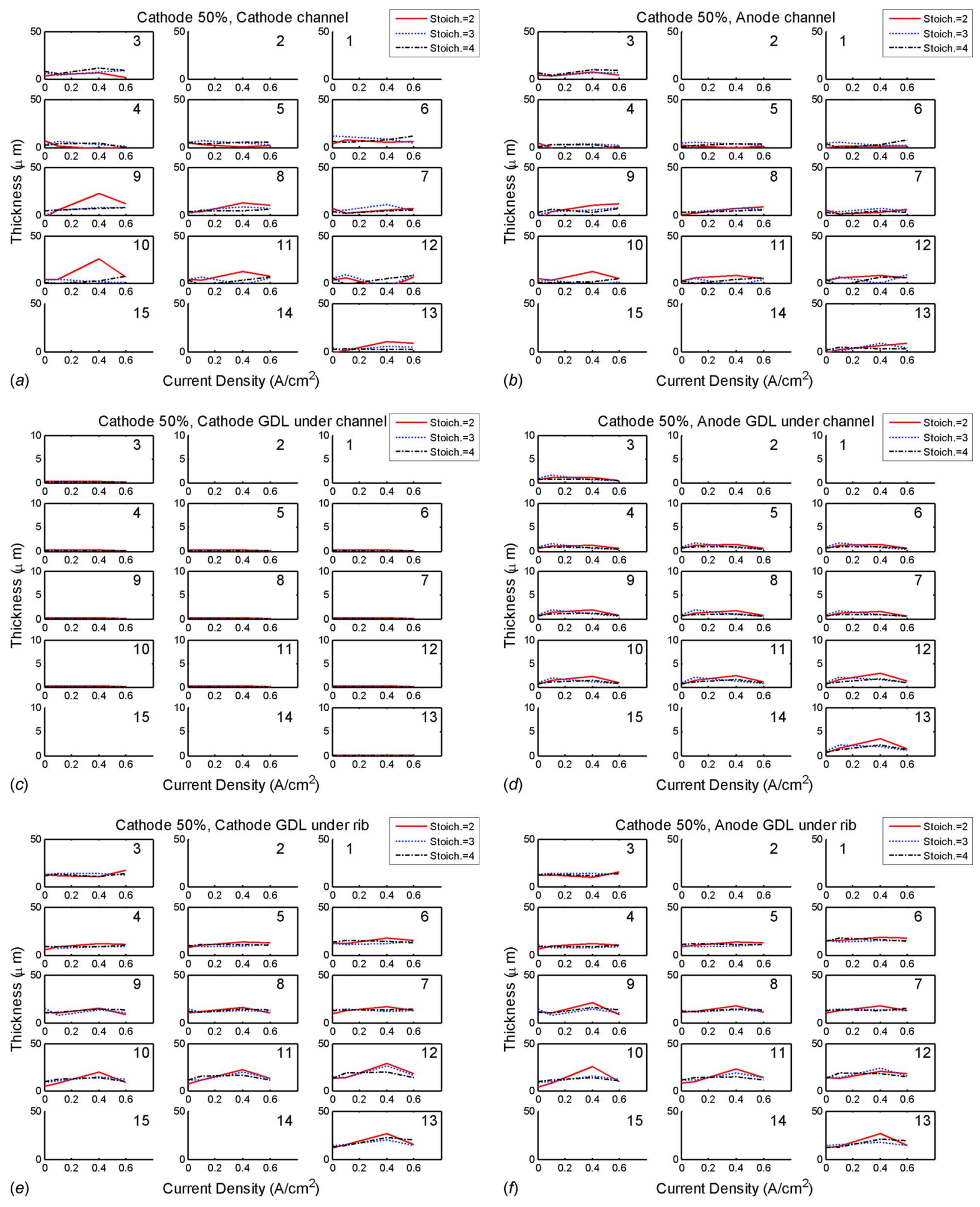

Fig. 9 Average liquid water thicknesses in the (a) cathode channel, (b) anode channel, (c) cathode GDL under the channel, (d) anode GDL under the channel, $(e)$ cathode GDL under the rib, and $(f)$ anode GDL under the rib when the cathode inlet RH is $50 \%$ 

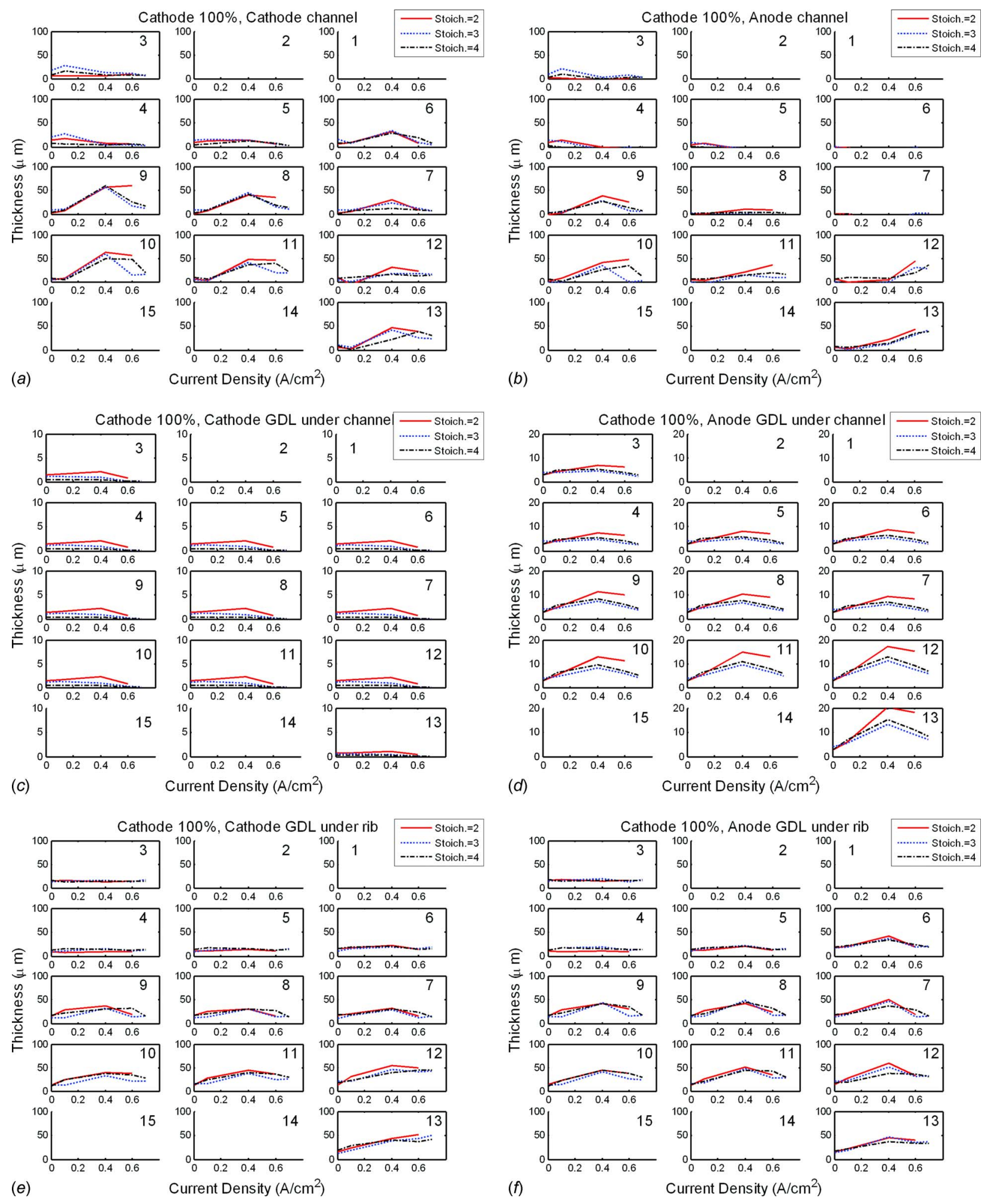

Fig. 10 Average liquid water thicknesses in the (a) cathode channel, (b) anode channel, (c) cathode GDL under the channel, $(d)$ anode GDL under the channel, $(e)$ cathode GDL under the rib, and $(f)$ anode GDL under the rib when the cathode inlet $\mathrm{RH}$ is $100 \%$ 

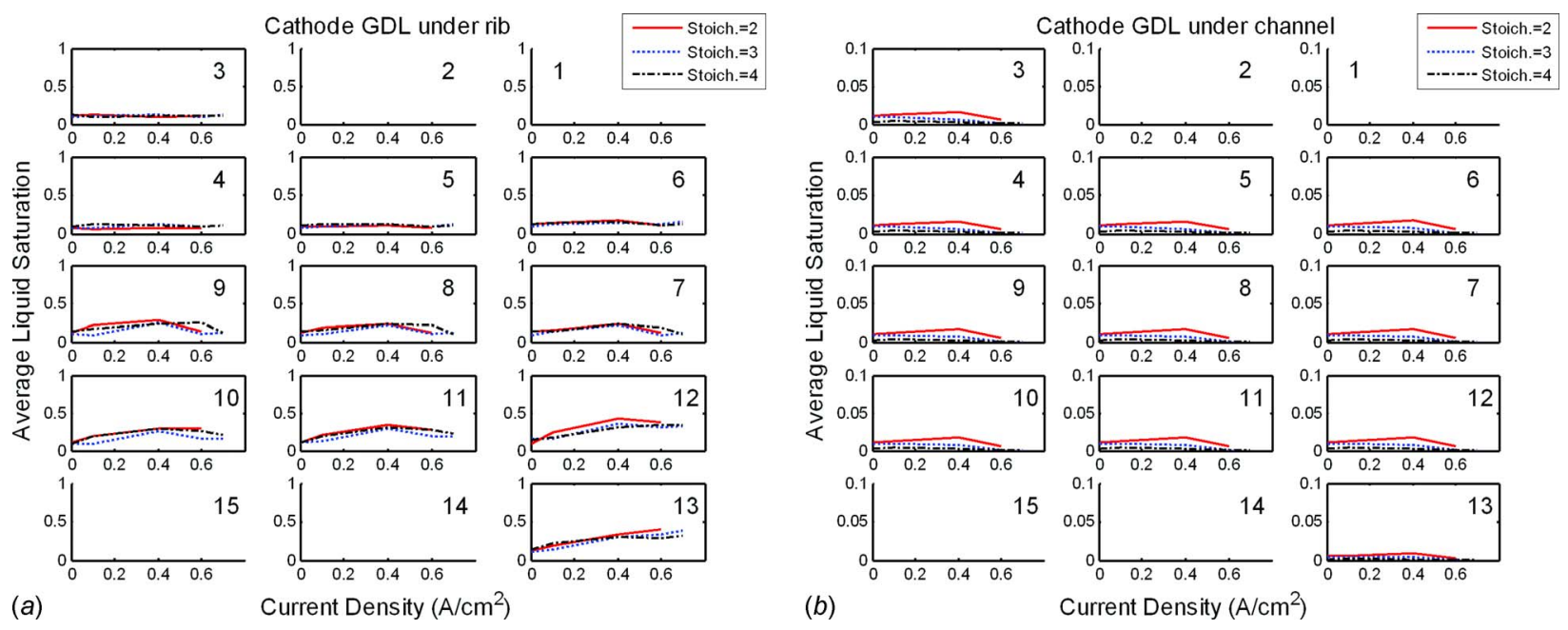

Fig. 11 Average liquid saturation in (a) the GDL under the rib and (b) the GDL under the channel

where

$$
\left[\begin{array}{llllllll}
\mathbf{S} & \mathbf{O} & \mathbf{O} & \mathbf{O} & \cdots & \mathbf{O} & \mathbf{a}_{1} & \mathbf{b}_{1} \\
\mathbf{O} & \mathbf{S} & \mathbf{O} & \mathbf{O} & & \mathbf{O} & \mathbf{a}_{2} & \mathbf{b}_{2} \\
\mathbf{O} & \mathbf{O} & \mathbf{S} & \mathbf{O} & & \mathbf{O} & \mathbf{a}_{3} & \mathbf{b}_{3} \\
\mathbf{O} & \mathbf{O} & \mathbf{O} & \mathbf{S} & & \mathbf{O} & \mathbf{a}_{4} & \mathbf{b}_{4} \\
\vdots & \vdots & \vdots & \vdots & \ddots & \vdots & \vdots & \vdots \\
\mathbf{O} & \mathbf{O} & \mathbf{O} & \mathbf{O} & \cdots & \mathbf{S} & \mathbf{a}_{15} & \mathbf{b}_{15}
\end{array}\right]\left[\begin{array}{l}
\mathbf{y}_{1} \\
\mathbf{y}_{2} \\
\mathbf{y}_{3} \\
\mathbf{y}_{4} \\
\vdots \\
\mathbf{y}_{15} \\
\alpha \\
\beta
\end{array}\right]=\left[\begin{array}{l}
\mathbf{T}_{1} \\
\mathbf{T}_{2} \\
\mathbf{T}_{3} \\
\mathbf{T}_{4} \\
\vdots \\
\mathbf{T}_{15}
\end{array}\right]
$$

$$
\mathbf{S}=\left[\begin{array}{ll}
1 & 1 \\
0 & 1 \\
1 & 0
\end{array}\right], \quad \mathbf{O}=\left[\begin{array}{ll}
0 & 0 \\
0 & 0 \\
0 & 0
\end{array}\right], \quad \mathbf{a}_{i}=\left[\begin{array}{c}
1 \\
N_{c a, i} \\
0 \\
\frac{1}{N_{c a, i}}
\end{array}\right], \quad \mathbf{b}_{i}=\left[\begin{array}{c}
\frac{1}{N_{a n, i}} \\
\frac{1}{N_{a n, i}} \\
0
\end{array}\right]
$$

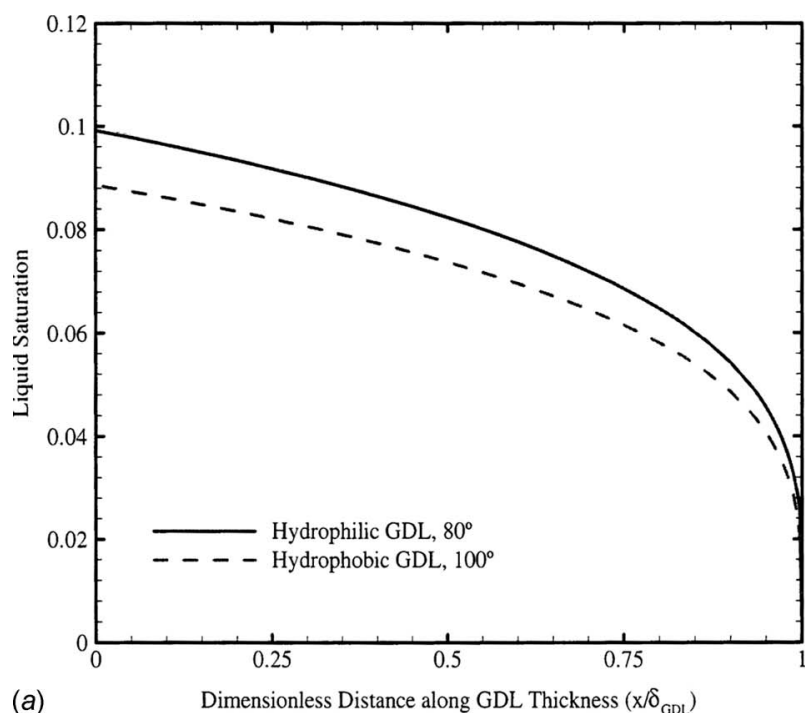

In the vector $\mathbf{T}_{i}$,

$$
\mathbf{y}_{i}=\left[\begin{array}{c}
C_{c, i} \\
A_{c, i}
\end{array}\right], \quad \mathbf{T}_{i}=\left[\begin{array}{l}
\mathrm{NewCC}_{i} \\
\mathrm{NewCR}_{i} \\
\mathrm{NewAR}_{i}
\end{array}\right]
$$

$$
\begin{gathered}
\mathrm{NewCC}_{i}=\mathrm{CC}_{i}-C_{g r, i}-A_{g r, i} \\
\mathrm{NewCR}_{i}=\mathrm{CR}_{i}-C_{g r, i} \\
\mathrm{NewAR}_{i}=\mathrm{AR}_{i}-A_{g r, i}
\end{gathered}
$$

By using least-squares method (LSM) [26], we can solve Eq. (6) to find out $C_{c, i}, A_{c, i}, \alpha$, and $\beta$. From Eq. (5), $C_{g c}$ and $A_{g c}$ can then be solved. However, due to the shifted flow field design in this study, not every segment always has measured data in four areas. Thus, only segments 3-13 can be calculated by using this method. If a nonshifted cell design was used, i.e., if anode and cathode flow fields overlap, there will only be two measured data,

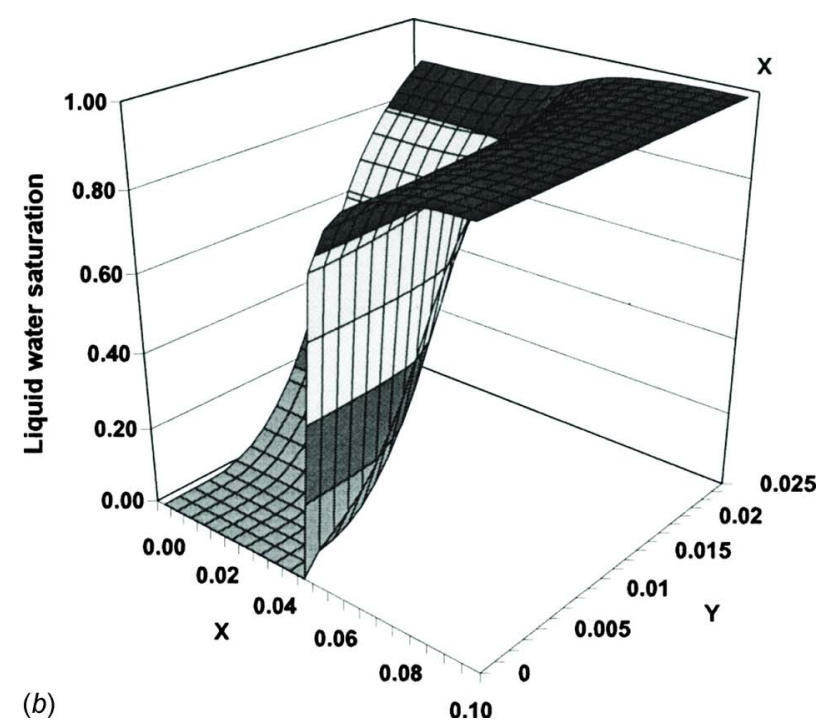

Fig. 12 Liquid saturation in the GDL. (a) The study of Pasaogullari and Wang [9] models the liquid saturation in the GDL under the channel. (b) The study of Natarajan and Nguyen [10] models the liquid saturation in the GDL under the channel and under the rib. 
$\mathrm{RH}$ distribution in the cathode (cathode inlet $\mathrm{RH}=50 \%$ )
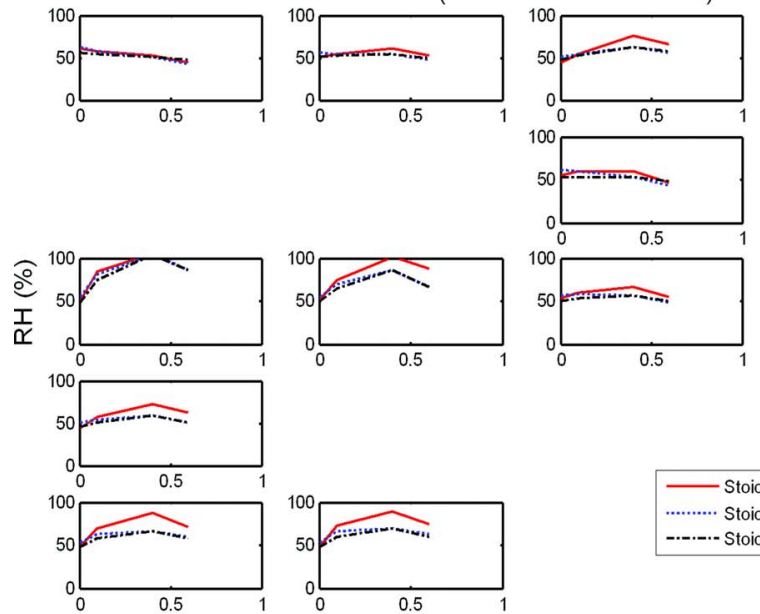

(a)

Current Density $\left(\mathrm{A} / \mathrm{cm}^{2}\right)$
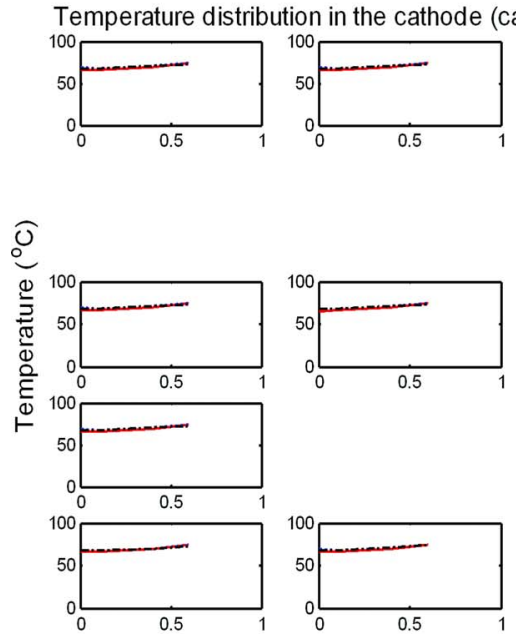

(c)
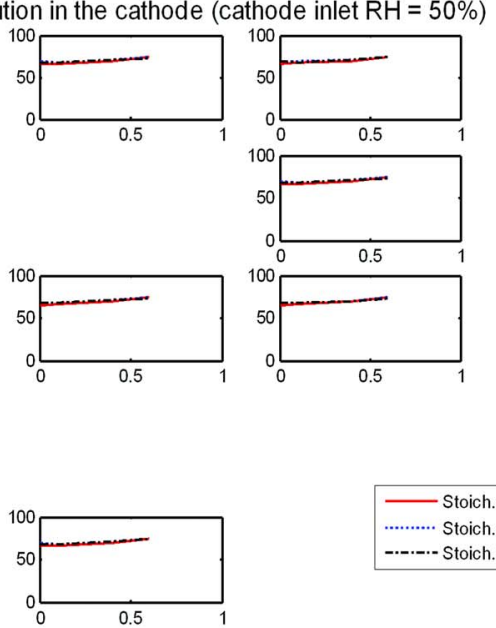

Current Density $\left(A / \mathrm{cm}^{2}\right)$

$\mathrm{RH}$ distribution in the anode (cathode inlet $\mathrm{RH}=50 \%$ )
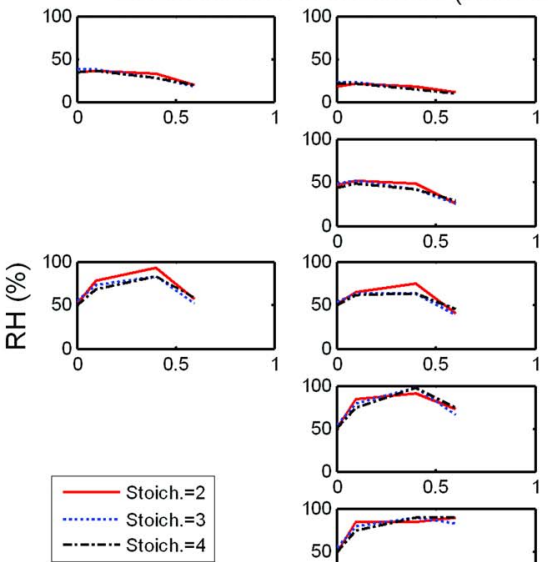

(b)
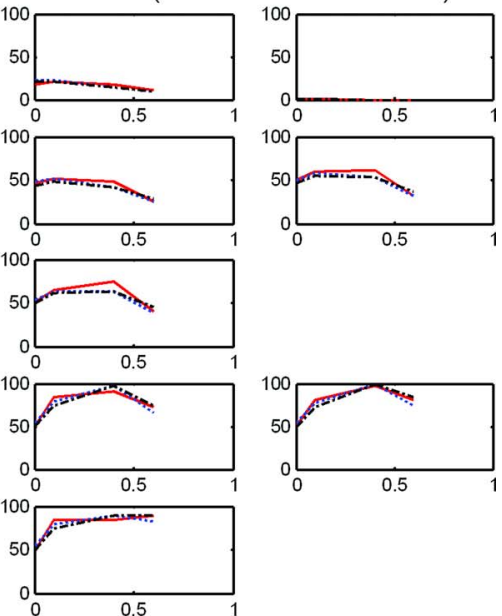

Current Density $\left(\mathrm{A} / \mathrm{cm}^{2}\right)$
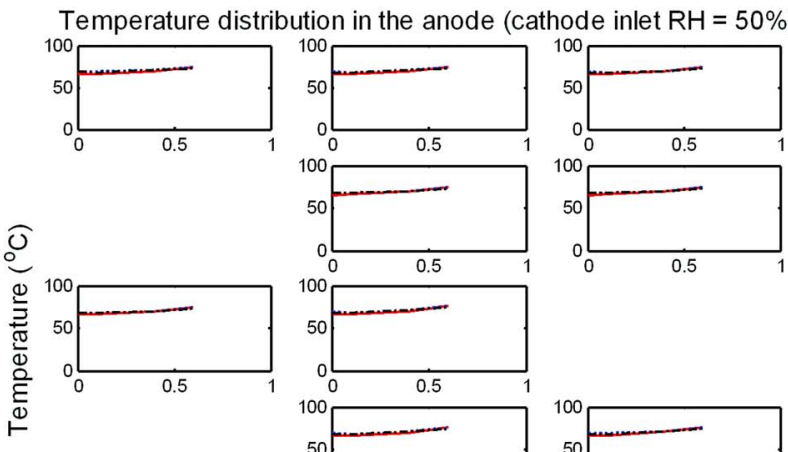

Fig. 13 Relative humidity distribution in the (a) cathode channel and (b) anode channel. Temperature distribution in the (a) cathode channel and (b) anode channel when the cathode inlet $\mathrm{RH}$ is $50 \%$.

$\mathrm{CC}$ and RR, from neutron imaging. This will result in two fewer equations for each segment, which increases the degree of freedom of the solution and thus the inferior solution from the underdeterminant problem.

3.2 Steady-State Conditions. Figures 9 and 10 show the results of using LSM to differentiate water accumulation in the six locations when the cathode inlet RH values are $50 \%$ and $100 \%$, respectively. Figures $9(d)$ and $9(f)$ suggest that water thickness in the anode GDLs decreases when current density is high. This phenomenon becomes more pronounced when the cathode inlet RH is $100 \%$, as shown in Figs. $10(d)$ and $10(f)$. The decrease in water content at high current density is likely due to the water transport by electro-osmotic drag from anode to cathode. Another possible reason is the high gas flow rate at high current density. Higher flow rate gas takes more liquid water out from the GDLs.

Both Figs. 9(c) and 10(c) show little liquid water in the cathode GDL under the channel. This trend was also observed in the study of Zhang et al. [20] when the reactants were fully humidified. A possible reason is that due to the high stoichiometric value in the cathode side, the flow rate in the cathode is higher than that in the anode. Figures 9 and 10 also show that water content at a low stoichiometry value is slightly more than that at a high stoichiometry value. This is because when the gas flow rate is low, less water in the GDLs is carried away by the gas flow, resulting in more water accumulation in the GDLs.

In Fig. 9, it can be seen that when the cathode inlet RH is $50 \%$, water content in the GDLs does not change with current densities. Because of the low RH of the inlet cathode gas, the generated liquid water is quickly taken from GDLs by unsaturated gas flow. When the cathode inlet is fully humidified, more liquid water accumulates in the cathode GDL under the rib. Figures 10(e) and $10(f)$ show that the maximum water thickness in the GDLs under the cathode rib and under the anode rib is around $50 \mu \mathrm{m}$, which could be the maximum amount of water that can accumulate in the GDLs under those operating conditions. Once water is generated in the cathode catalyst layer, it has the tendency to move from the hydrophobic GDL into the channels. If the GDL cannot expel liquid water effectively, liquid saturation in the GDL and catalyst layer will be large, which is commonly referred to as flooding.

Liquid saturation can be precisely quantified by the ratio of the liquid volume to the pore volume in the GDL. This ratio directly relates to how much of the available volume for reactant flow has been occupied by liquid water and thus reflects the extent of GDL "flow blockage." Pasaogullari and Wang [9] and Natarajan and Nguyen [10] developed different empirical models to study the distribution of liquid saturation along the thickness of GDLs. The liquid saturation in GDL is not easy to measure by using a mono- 
$\mathrm{RH}$ distribution in the cathode (cathode inlet $\mathrm{RH}=100 \%$ )
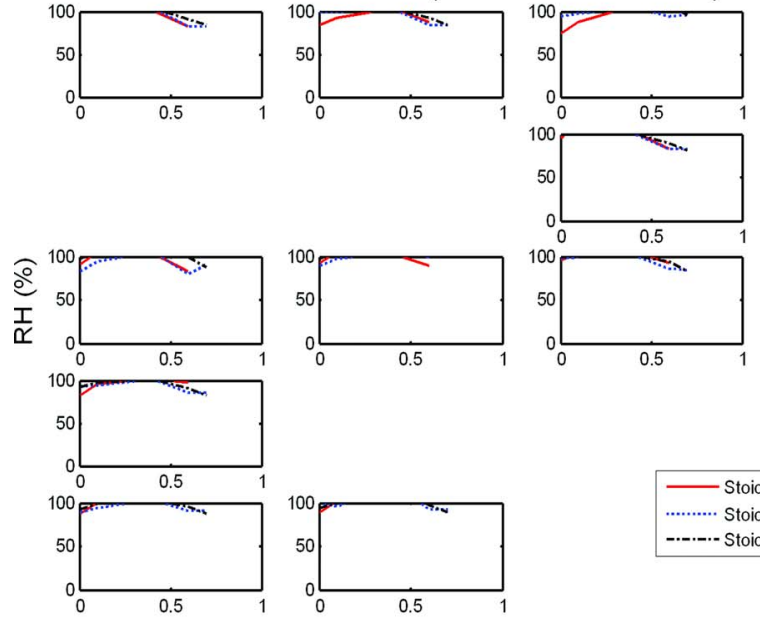

(a)

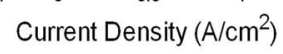

Temperature distribution in the cathode (cathode inlet $\mathrm{RH}=100 \%$ )
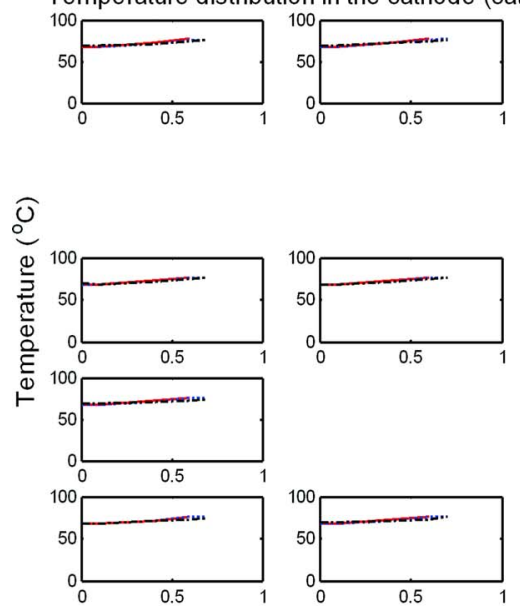

(c)
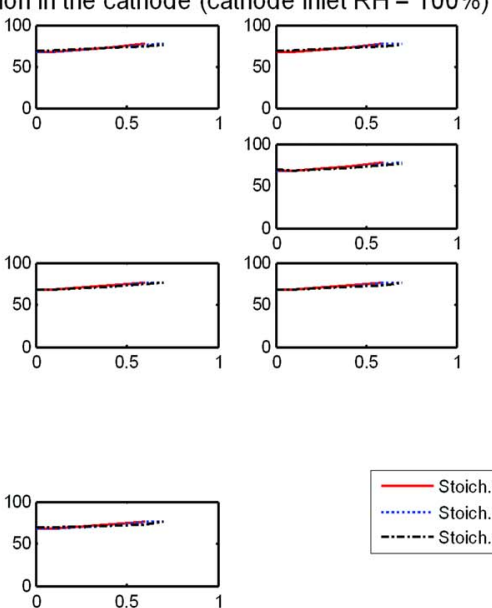

Current Density $\left(\mathrm{A} / \mathrm{cm}^{2}\right)$
$\mathrm{RH}$ distribution in the anode (cathode inlet $\mathrm{RH}=100 \%$ )
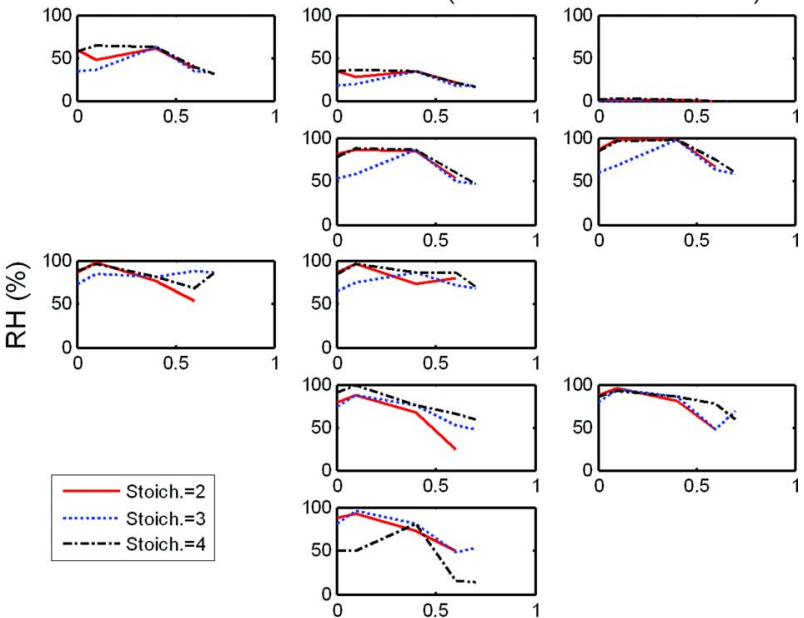

(b)

Current Density $\left(\mathrm{A} / \mathrm{cm}^{2}\right)$

Temperature distribution in the anode (cathode inlet $\mathrm{RH}=100 \%$ )
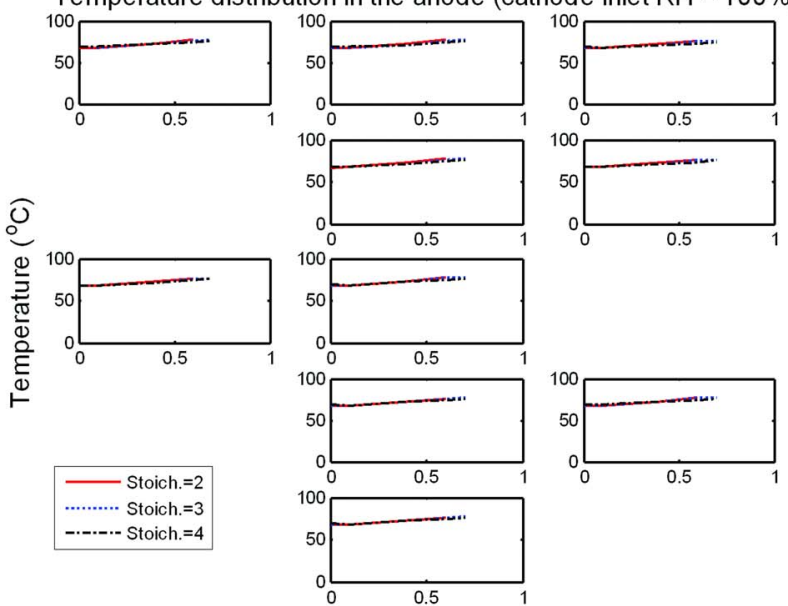

(d)

Fig. 14 Relative humidity distribution in the (a) cathode channel and (b) anode channel. Temperature distribution in (a) cathode channel and $(b)$ anode channel when the cathode inlet RH is $100 \%$.

neutron beam-it will be possible, in theory, to obtain that information by using accurate stereo imaging. Unfortunately, such capability was not available when we conducted the experiment. Therefore, from the test data we can only calculate the average liquid saturation, which can be calculated by

$$
s=\frac{t_{w} \cdot A}{t_{\mathrm{GDL}} \cdot A \cdot \varepsilon}=\frac{t_{w}}{t_{\mathrm{GDL}} \cdot \varepsilon}
$$

where $t_{w}$ is the average water thickness in the GDLs, $t_{\mathrm{GDL}}$ is the GDL thickness, $A$ is the segment area, and $\varepsilon$ is the porosity of GDLs.

The cathode of the PEMFC is the performance-constraint component due to the slower kinetics of oxygen reduction and the mass-transfer limitations caused by liquid water generation and the existence of a large quantity of nitrogen. Thus, in the following only cathode liquid saturation is calculated and compared with other groups' studies. Figure 11 shows the result of using Eq. (9) to calculate average liquid saturation in the cathode GDLs. Figure 11(a) shows that average liquid saturation in the GDL under the ribs varies from 0.05 to 0.5 , whereas that in the GDL under the channels is below 0.02, as shown in Fig. 11(b). Figure 12 shows the modeling results from the studies of Pasaogullari and Wang [9] and Natarajan and Nguyen [10]. The model of Pasaogullari and Wang describes the distribution of liquid saturation in the
GDL under the channels only, and the average value is close to 0.07. The model of Natarajan and Nguyen shows threedimensional liquid saturation distribution in the GDLs both under the channels and under the ribs. The liquid saturation in the GDL under the ribs is higher than 0.9, whereas that in the GDL under the channel varies between 0 and 0.88 .

Figures $13(a)$ and $13(b)$ show relative humidity distribution in the cathode and anode when the cathode inlet $\mathrm{RH}$ is $50 \%$. The RH in each segment increases with increasing current density. This is because water generation increases with increasing current density. However, at high current density $\left(0.6 \mathrm{~A} \mathrm{~cm}^{-2}\right), \mathrm{RH}$ values decrease slightly. It could be due to the high flow rate of unsaturated gas at high current density. Moreover, Fig. 13(a) shows that $\mathrm{RH}$ in the cathode channel at a stoichiometry of 2 is slightly higher than those at stoichiometry of 3 and 4 . These phenomena suggest small flow rate results in higher $\mathrm{RH}$ values in the channels. On the other hand, when the cathode inlet $\mathrm{RH}$ is $100 \%$, stoichiometry values do not influence $\mathrm{RH}$ in the channels, as shown in Fig. 14(a). Figures 13(c), 13(d), 14(c), and 14(d) show that segment temperatures increase slightly with current density, but the temperature difference between segments can be neglected regardless of the stoichiometric values and the cathode inlet RH.

The experimental results in this study suggest that liquid water in the GDL under the ribs varies with current load and operating 

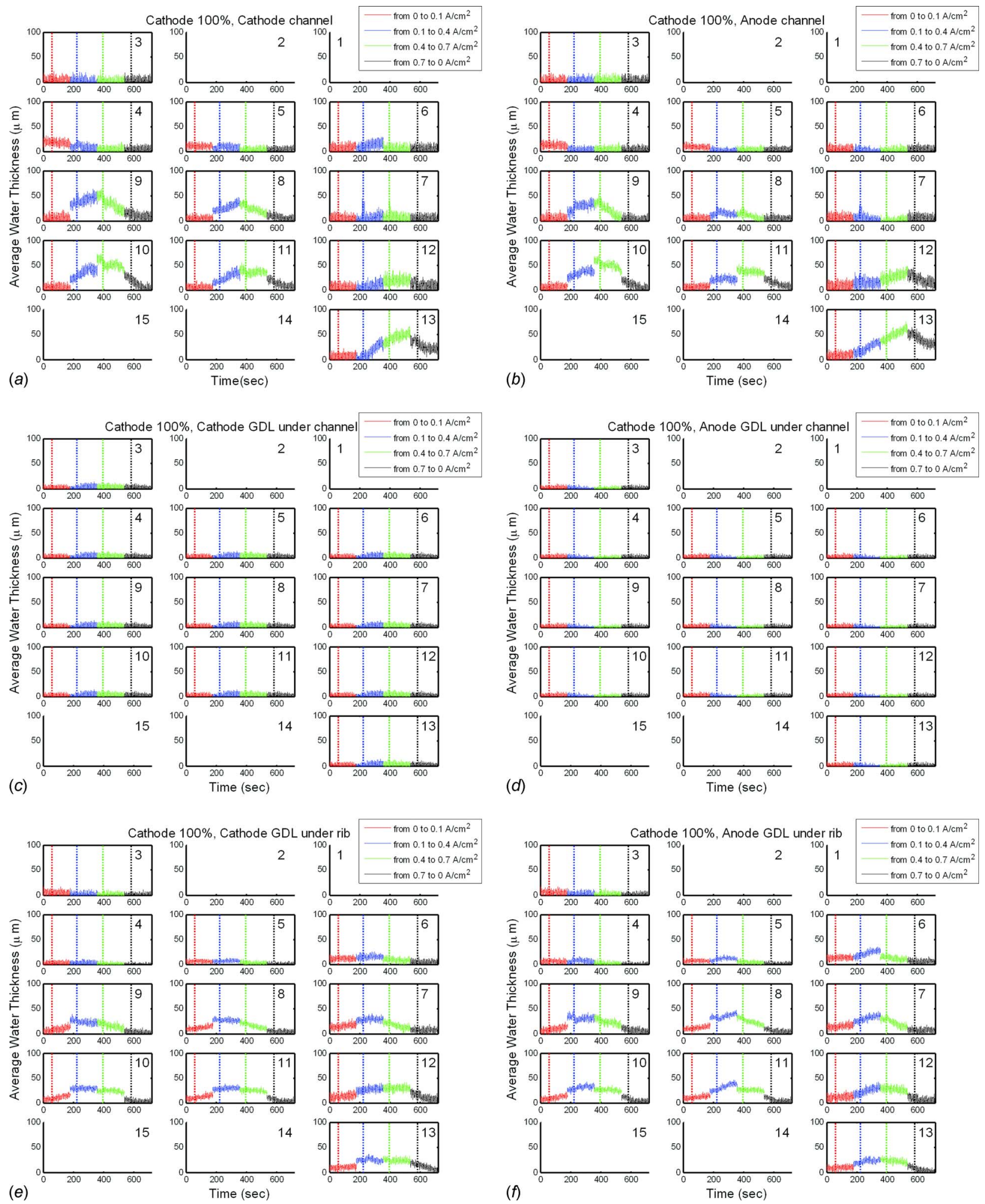

Fig. 15 Step response of average liquid water thickness in the (a) cathode channel, (b) anode channel, (c) cathode GDL under the channel, (d) anode GDL under the channel, (e) cathode GDL under the rib, and ( $f$ ) anode GDL under the rib when the cathode inlet $\mathrm{RH}$ is $100 \%$

conditions, whereas that in the GDL under the channels is not significantly influenced by operating conditions. In addition, these distributed data also provide us useful information to develop a fuel cell model.

3.3 Transient Behavior of Water Transport. The transient behavior of water transport was studied by plotting water thickness and measured RH values in the anode and cathode channels versus time. To save space, four operating conditions were plotted in a figure. The moment when a load change was applied was marked by vertical dashed lines in the figures, and the test data 

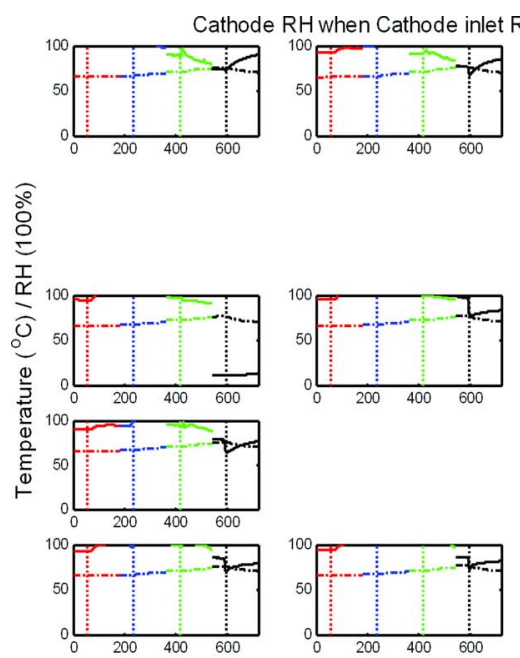

(a)
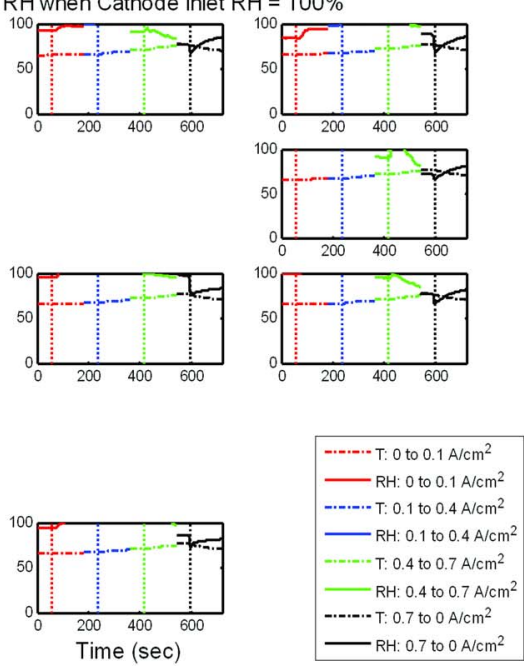

Fig. 16 $100 \%$

shown in Fig. 15 include 1 min before the step change and 2 min after. Figure 15 shows that the water thickness changes with respect to time when the cathode inlet gas is $100 \%$. These plots suggest that water contents in those six locations do not change immediately with load change. In other words, after current density is changed, it takes time for the water content in the fuel cell to reach steady-state.

Figure $15(a)$ shows that liquid water in segment 13 gradually increases when current density changes from $0.4 \mathrm{~A} \mathrm{~cm}^{-2}$ to $0.7 \mathrm{~A} \mathrm{~cm}^{-2}$, whereas liquid water in other segments decreases or remains constant. It is possible that due to the channel-reduction design (from 12 channels to 6 channels) in the cathode, more liquid water is carried to the outlet, which encountered a bottleneck at segment 13. The liquid water in the GDL under the rib does not increase with time, as shown in segment 13 in Fig. 15(e). This result suggests that the channel-reduction design reduces flooding in the GDLs.

Figures $16(a)$ and $16(b)$ show the RH values and temperature in the cathode and anode channels. When the cell is operated at low current densities, the RH in the anode channel increases with the

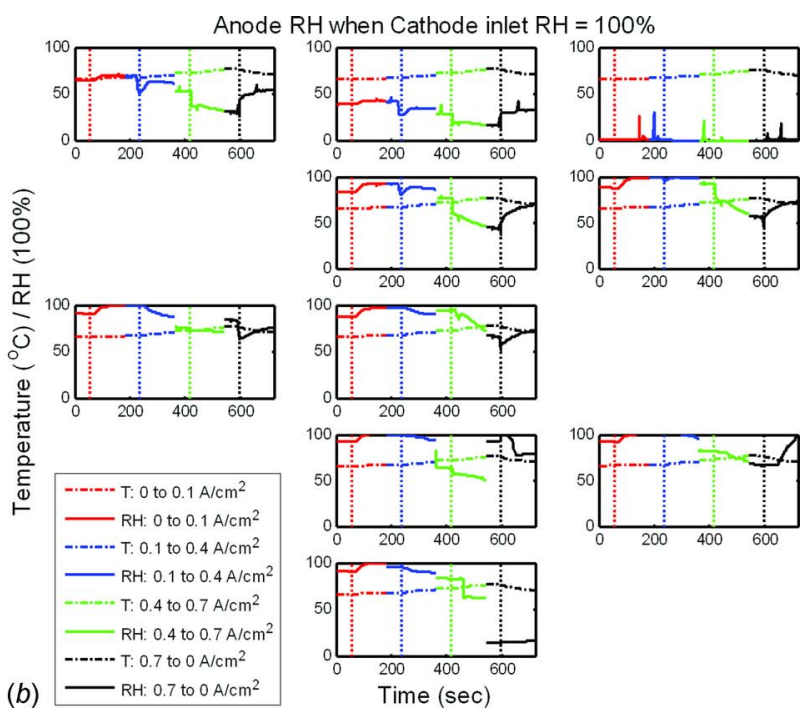

(b)

ow distance quickly and typically reaches saturation after onethird of the flow distance. However, when the current density changes from $0.4 \mathrm{~A} \mathrm{~cm}^{-2}$ to $0.7 \mathrm{~A} \mathrm{~cm}^{-2}, \mathrm{RH}$ in the anode channel decreases to approximately 50\% due to the electro-osmotic drag. Figure 15(b) shows that there is some liquid water in the anode channel, but RH sensors in Fig. 16(b) do not report 100\%. The possible reason is that the mass-transfer rate due to liquid water evaporation is lower than that due to anode gas flow at high current density.

Figures $17(a)$ and $17(b)$ show a RH difference between the cathode and anode channels when the cathode inlet RH is $50 \%$. At the current density of $0 \mathrm{~A} \mathrm{~cm}^{-2}$, i.e., no liquid water generated inside the fuel cell, RH in the anode channel increases along the channel to $50 \%$. When the current density increases to $0.1 \mathrm{~A} \mathrm{~cm}^{-2}$, the RH values in the anode channel increase approximately to $75 \%$, which is higher than that in the cathode channel. When the current density changes from $0.1 \mathrm{~cm}^{-2}$ to $0.4 \mathrm{~cm}^{-2}$, the RH values in the anode channel reports $100 \%$. Since the anode inlet gas is not humidified, the only way for the anode gas to
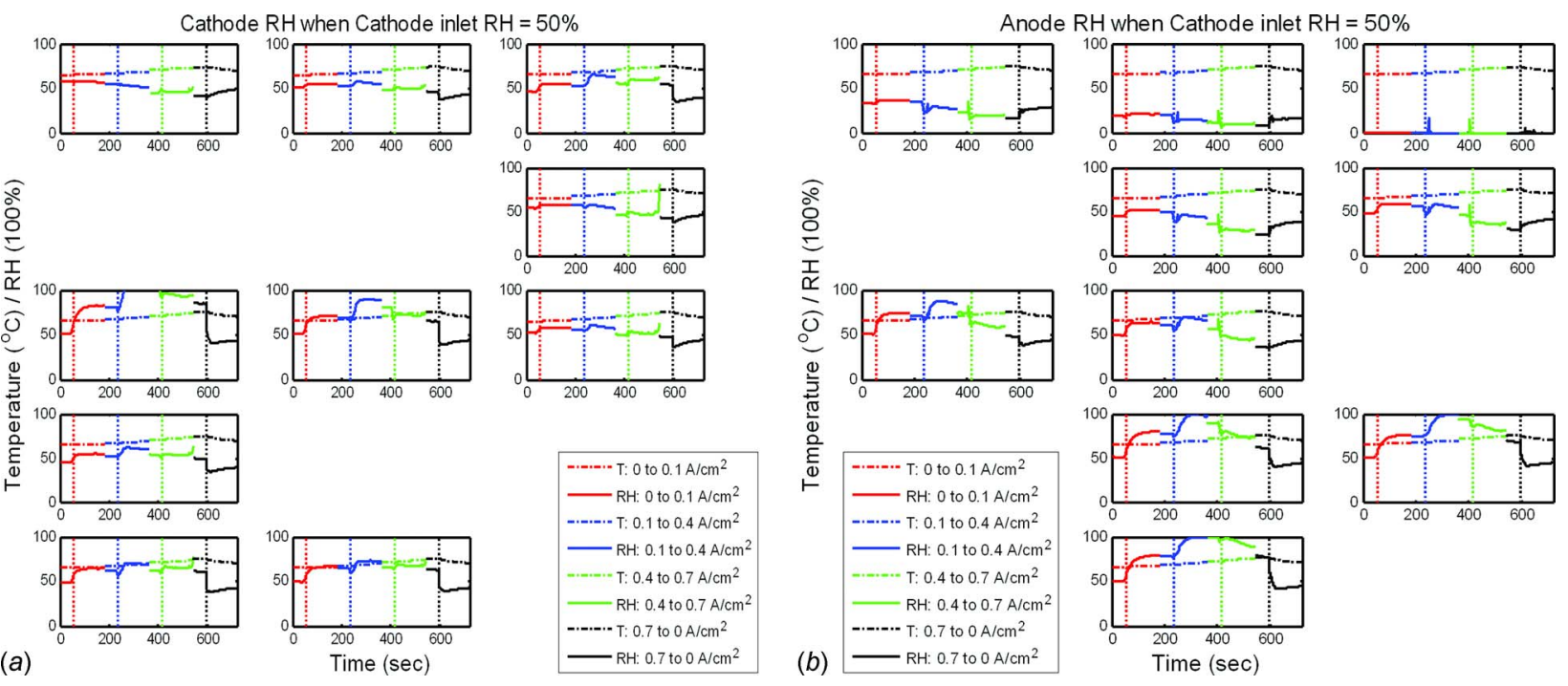

Fig. 17 Step response of relative humidity in the (a) cathode channel and (b) anode channel when the cathode inlet RH is $50 \%$ 
acquire water is through backdiffusion from the cathode to the anode. Moreover, the cathode stoichiometry is higher than the anode stoichiometry; i.e., the cathode gas flow rate is higher than the anode gas flow rate. Therefore, water in the anode channel is slowly removed, resulting in the increase of $\mathrm{RH}$ in the anode channels.

Figures 16 and 17 also show the temperature distribution measured by RH sensors within the fuel cell. Since we only have ten $\mathrm{RH}$ sensors for each of the anode/cathode side, some of the segments have no temperature data reported. Subplots are arranged corresponding to RH sensor positions. Regardless of the cathode inlet $\mathrm{RH}$ values, temperatures at each segment change slowly after sudden current changes. In addition, there is no significant temperature variation throughout the active area. There is little spatial variation of temperature at all current density levels. High thermal conductivity of graphite $\left(140 \mathrm{~W} \mathrm{~m}^{-1} \mathrm{~K}^{-1}\right)$ and reactant flow both contribute to the uniform temperature. This result implies that temperature distribution can be considered to be uniform in a single cell, which helps to reduce the complexity of a segmented single cell model in our future study.

The specially designed single cell, together with image processing techniques and LSM, provides a new way to investigate liquid water accumulation in an operating fuel cell. These results show the influence of stoichiometry and RH values of the cathode inlet on water distribution within a fuel cell. These experimental results are useful to validate our fuel cell model, which is in progress.

\section{Conclusions}

Neutron radiography provides a nondestructive and valuable measurement technique to quantify and visualize liquid water in a working PEMFC. A single cell with shifted flow field design as well as imaging mask techniques was used to differentiate liquid water in four types of channel/rib combinations: anode channel/ cathode channel, anode rib/cathode rib, anode channel/cathode rib, and cathode channel/anode rib. By applying the LSM, the average liquid water thicknesses in the GDL under the channel, in the GDL under the ribs, and in the channels were able to be calculated. In this study, both steady-state and transient behaviors of water accumulation were studied at different cathode inlet conditions.

The influence of the cathode inlet RH and stoichiometry values on liquid water accumulation and distribution was studied in this paper. The RH of the cathode inlet was shown to have a substantial effect on liquid water accumulation in the GDLs. The steadystate experimental results showed that liquid water has a tendency to accumulate in the GDL under the rib and varies with current densities. The average liquid saturation in the GDL under the rib was found to vary from 0.05 to 0.5 and that in the GDL under the channel is about 0.02 , which is lower than modeling results in the literature. The RH in each segment increases with increasing current density due to water generation. At high current density, a slight decrease in $\mathrm{RH}$ values could be due to the high flow rate of unsaturated gas. Moreover, temperature difference between segments can be neglected regardless of the stoichiometric values and cathode inlet RH.

The transient behavior of water transport was studied by capturing neutron images and $\mathrm{RH}$ in the flow channels. The channelreduced design in the cathode helps gas flow to carry liquid water to the outlet without causing flooding in the GDLs. In addition, $\mathrm{RH}$ in the anode channel quickly increases with flow distance and reaches saturation even when the cathode $\mathrm{RH}$ is unsaturated. At high current density, RH in the anode channel decreases due to the higher dry anode gas flow rate. The temperature distributes uniformly within the active area and has large response time with respect to load change.

\section{Acknowledgment}

The authors would like to acknowledge the support of National Science Foundation (Grant No. NSF0408664) for their research at the University of Michigan. The authors would also like to express their gratitude to Dr. B. J. Weng of the Chung-Shan Institute of Science and Technology, Taiwan for manufacturing the fuel cell components and Rob Privette of Umicore for providing the membrane electrode assemblies. In addition we acknowledge that this work was supported by the U.S. Department of Commerce, the NIST Ionizing Radiation Division, the Director's Office of NIST, the NIST Center for Neutron Research, and the Department of Energy through interagency Agreement No. DE-AI01$01 \mathrm{EE} 50660$.

\section{References}

[1] Bernardi, D. M., and Verbrugge, M. W., 1991, "Mathematical Model of a Gas Diffusion Electrode Bonded to a Polymer Electrolyte," AIChE J., 37(8), pp. 1151-1163.

[2] Bernardi, D. M., and Verbrugge, M. W., 1992, "A Mathematical Model of the Solid-Polymer-Electrolyte Fuel Cell,” J. Electrochem. Soc., 139(9), pp. 2477 2491.

[3] Springer, T. E., Zawodzinski, T. A., and Gottesfeld, S., 1991, "Polymer Electrolyte Fuel Cell Model,” J. Electrochem. Soc., 138(5), pp. 2334-2342.

[4] Wang, C. Y., Gu, W. B., and Liaw, B. Y., 1998, "Micro-Macroscopic Coupled Modeling of Batteries and Fuel Cells," J. Electrochem. Soc., 145(10), pp. $3407-3417$

[5] Um, S., Wang, C. Y., and Chen, K. S., 2000, "Computational Fluid Dynamics Modeling of Proton Exchange Membrane Fuel Cells," J. Electrochem. Soc., 147(12), pp. 4485-4493.

[6] Fuller, T. F., and Newman, J., 1993, "Water and Thermal Management in Solid-Polymer-Electrolyte Fuel Cells," J. Electrochem. Soc., 140(5), pp. $1218-1225$.

[7] Baschuk, J. J., and Li, X., 2000, "Modeling of Polymer Electrolyte Membrane Fuel Cells With Variable Degrees of Water Flooding," J. Power Sources, 86(1-2), pp. 181-196.

[8] Wang, Z. H., Wang, C. Y., and Wang, K. S., 2001, "Two-Phase Flow and Transport in the Air Cathode of Proton Exchange Membrane Fuel Cells," J. Power Sources, 94(1), pp. 40-50

[9] Pasaogullari, U., and Wang, C. Y., 2004, "Liquid Water Transport in Gas Diffusion Layer of Polymer Electrolyte Fuel Cells," J. Electrochem. Soc., 151(3), pp. A399-A406.

[10] Natarajan, D., and Nguyen, T. V., 2001, "A Two-Dimensional, Two-Phase, Multicomponent, Transient Model for the Cathode of a Proton Exchange Membrane Fuel Cell Using Conventional Gas Distributors," J. Electrochem. Soc., 148(12), pp. A1324-A1335.

[11] Lin, G., and Nguyen, T. V., 2006, "A Two-Dimensional Two-Phase Model of a PEM Fuel Cell,” J. Electrochem. Soc., 153(2), pp. A372-A382.

[12] Nishikawa, H., Kurihara, R., Sukemori, S., Sugawara, T., Kobayasi, H., Abe S., Aoki, T., Ogami, Y., and Matsunaga, A., 2006, "Measurements of Humidity and Current Distribution in a PEFC," J. Power Sources, 155(2), pp. 213-218.

[13] Mench, M. M., Dong, Q. L., and Wang, C. Y., 2003, "In Situ Water Distribution Measurements in a Polymer Electrolyte Fuel Cell," J. Power Sources, 124(1), pp. 90-98.

[14] Tüber, K., Pócza, D., and Hebling, C., 2003, "Visualization of Water Buildup in the Cathode of a Transparent PEM Fuel Cell," J. Power Sources, 124(2), pp. 403-414.

[15] Pekula, N., Heller, K., Chuang, P. A., Turhan, A., Mench, M. M., Brenizer, J. S., and Ünlü, K., 2005, "Study of Water Distribution and Transport in a Polymer Electrolyte Fuel Cell Using Neutron Imaging," Nucl. Instrum. Methods Phys. Res. A, 542(1-3), pp. 134-141.

[16] Chuang, P. A., Turhan, A., Heller, A. K., Brenizer, J. S., Trabold, T. A., and Mench, M. M., 2005, "The Nature of Flooding and Drying in Polymer Electrolyte Fuel Cells," Proceedings of the Third ASME International Conference on Fuel Cell Science, Engineering and Technology.

[17] Turhan, A., Heller, K., Brenizer, J. S., and Mench, M. M., 2006, "Quantification of Liquid Water Accumulation and Distribution in a Polymer Electrolyte Fuel Cell Using Neutron Imaging," J. Power Sources, 160(2), pp. 1195-1203.

[18] Geiger, A. B., Tsukada, A., Lehmann, E., Vontobel, P., Wokaun, A., and Scherer, G. G., 2002, "In Situ Investigation of Two-Phase Flow Patterns in Flow Fields of PEFC's Using Neutron Radiography," Fuel Cells, 2(2), pp. 92-98.

[19] Kramer, D., Zhang, J., Shimoi, R., Lehmann, E., Wokaun, A., Shinohara, K. and Scherer, G. G., 2005, "In Situ Diagnostic of Two-Phase Flow Phenomena in Polymer Electrolyte Fuel Cells by Neutron Imaging: Part A. Experimental, Data Treatment, and Quantification," Electrochim. Acta, 50(13), pp. 26032614.

[20] Zhang, J., Kramer, D., Shimoi, R., Ono, Y., Lehmann, E., Wokaun, A., Shinohara, K., and Scherer, G. G., 2006, "In Situ Diagnostic of Two-Phase Flow Phenomena in Polymer Electrolyte Fuel Cells by Neutron Imaging, Part B: Material Variations," Electrochim. Acta, 51(13), pp. 2715-2727.

[21] Trabold, T. A., Owejan, J. P., Jacobson, D. L., Arif, M., and Huffman, P. R., 2006, "In Situ Investigation of Water Transport in an Operating PEM Fuel Cell Using Neutron Radiography, Part I: Experimental Method and Serpentine Flow Field Results,” Int. J. Heat Mass Transfer, 49(25-26), pp. 4712-4720.

[22] Owejan, J. P., Trabold, T. A., Jacobson, D. L., Baker, D. R., Hussey, D. S., and 
Arif, M., 2006, "In Situ Investigation of Water Transport in an Operating PEM Fuel Cell Using Neutron Radiography, Part II: Transient Water Accumulation in an Interdigitated Cathode Flow Field," Int. J. Heat Mass Transfer, 49(2526), pp. 4721-4731.

[23] Hickner, M. A., Siegel, N. P., Chen, K. S., McBrayer, D. N., Hussey, D. S. Jacobson, D. L., and Arif, M., 2006, "Real-Time Imaging of Liquid Water in an Operating Proton Exchange Membrane Fuel Cell," J. Electrochem. Soc., 153(5), pp. A902-A908
[24] Djilali, N., 2007, "Computational Modelling of Polymer Electrolyte Membrane (PEM) Fuel Cells: Challenges and Opportunities," Energy, 32(4), pp. 269-280.

[25] Hussey, D. S., Jacobson, D. L., Arif, M., Huffman, P. R., Williams, R. E., and Cook, J. C., 2005, "New Neutron Imaging Facility at the NIST," Nucl. Instrum. Methods Phys. Res. A, 542(1-3), pp. 9-15.

[26] Bay, J. S., 1998, Fundamentals of Linear State Space Systems, McGraw-Hill, New York, Chap. 3. 